\title{
In-vitro culture techniques of mini tomato for genomic study preparation
}

\author{
A Wahyudi ${ }^{1 *}$, Nazirwan ${ }^{1}$, F Yuniardi ${ }^{1}$ \\ ${ }^{1}$ Politeknik Negeri Lampung, Bandar Lampung, Indonesia \\ *Corresponding author:anung@polinela.ac.id
}

\begin{abstract}
Mini tomato cv. Micro-Tom is a plant favored by researchers because it has a short life cycle and small in size so that it becomes a practical plant and is suitable for representing research on tomato plants or other plants of the Solanaceae family. Unlike ordinary tomato plants which are large, take up space to grow, and sometimes have a long life cycle, making ordinary tomato plants a plant that is not so easy to handle. For that reason, the mini tomato is now described as a laboratory tomato. The aim of research is prepared mini tomato for genomic study. The research was conducted at Politeknik Negeri Lampung Tissue Culture Laboratory from April to September 2020. The material used for this research was mini tomato seeds. The explants used for the multiplication in this study were the cotyledons. These studies used macro elements, microelements, tomato vitamins, $\mathrm{CaCl}_{2}$, and $\mathrm{FeSO}_{4}$. EDTA to make Murashige and Skoog (MS) media, co-cultivation media, and callus induction media, shoot induction media, and root induction media for generated tomato plants. We successfully developed a mini tomato until final root induction. The result of these studies will use for genomic study (next research).
\end{abstract}

\section{Introduction}

Plant tissue culture is a method or technique forisolating plant tissues, organs, cells, and protoplasts, making explants, and growing them in aseptic growth media so that these explants can grow and develop, organize and become perfect plants [1]. In tissue culture, various types of plants can be developed, one of which is Micro-Tom or better known as mini oriental tomatoes. The Micro-Tom mini tomato cultivar, which is produced by crossing the basket Florida cultivar and the Ohio 4013-3 cultivar. Mini tomato is not only an ideal home or garden plant for home gardening, but also a very important cultivar model for genomics and proteomics research with several advantages such as short/stunted size, short life cycle, easy fruit setting, fast-growing, and can grow under high-density fluorescent light [2]. According to [3], ripe fruit can be harvested immediately within 70-90 days after sowing. The appearance of the dwarf Micro-Tom about 10-20 cm in height and other advantages as mentioned above are thought to be because the Micro-Tom has several special mutations. The most widely known mutation alleles dwarf (d), brassinosteroid (BR)-associated with mutations responsible for plant small size, and self-pruning (sp), responsible for the appearance in Micro-Tom growth [4]. Miniature ( $\mathrm{min}$ ), this allele is thought to have contributed to the formation of small micro-tom plant sizes [5][6]. The aim of our study is to make effectively method for mini tomato in-vitro culture.

\section{Method}

This research was conducted at Tissue Culture Laboratory Politeknik Negeri Lampung from April to September 2020. The materials used for this research were Micro-Tom tomato seeds and other 
chemicals in tissue culture techniques. These studies used macro elements, microelements, tomato vitamins, $\mathrm{CaCl}_{2}$, and $\mathrm{FeSO}_{4}$. EDTA to make Murashige and Skoog (MS) media, co-cultivation media, and callus induction media, shoot induction media, and root induction media for generated tomato plants (Micro-Tom). The in-vitro techniques is explained in Figure 1.Micro-Tom (Solanum Lycopersicum cv 'Micro-Tom') was used as a model cultivar for tomato research in this study because it has some advantages such as small size, short life cycle, easy fruit setting, easy of growth, and capacity to grow under fluorescent lights at a high intensity.

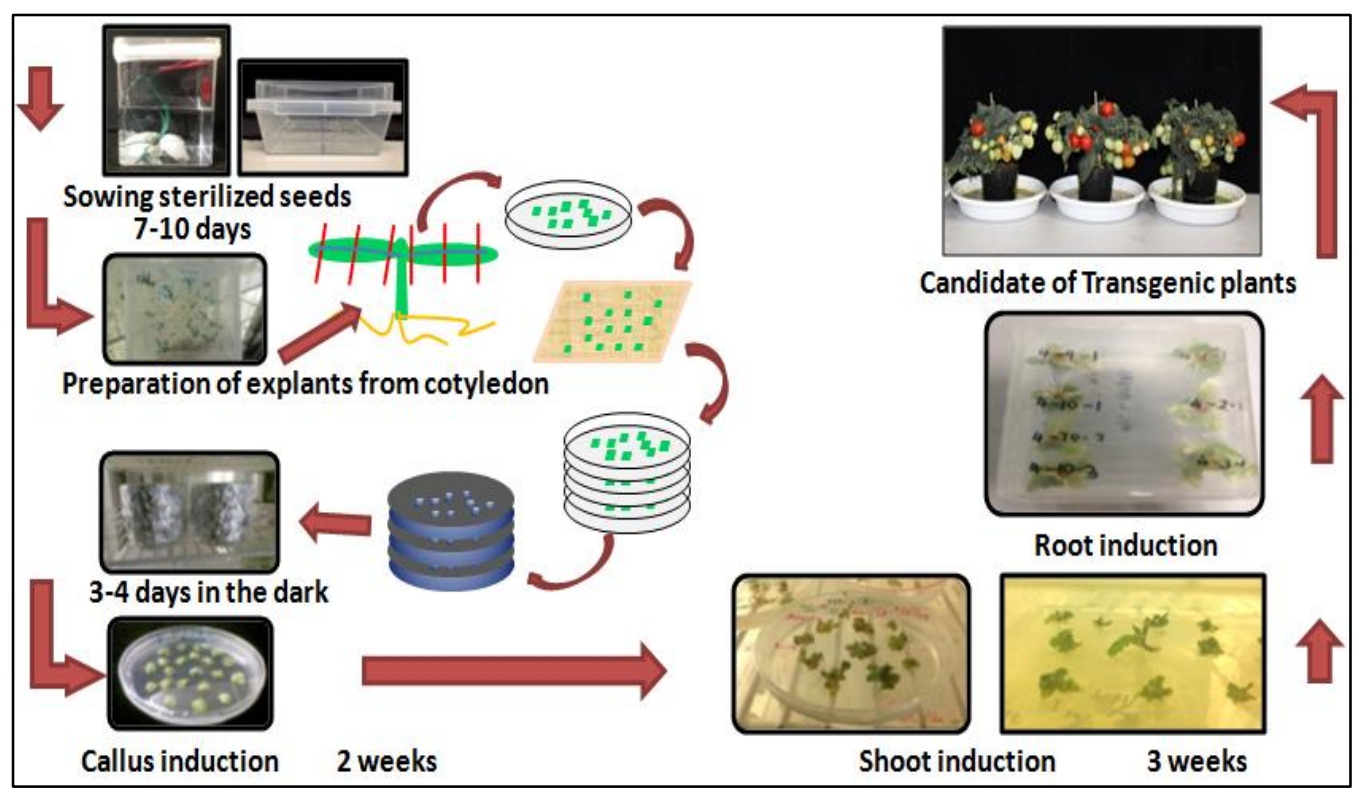

Figure 1. The in-vitro techniques of mini tomato cv. Micro-Tom [1].

\section{Result and Discussion}

The initial stage of the in-vitro culture on mini tomatoes in this study was seed sterilization. The seeds were wrapped in tile cloth, then soaked in a disinfectant solution (sulfactari and $\mathrm{NaClO}$ ) $10 \%$ for 45 minutes. Furthermore, the seeds are soaked in $96 \%$ ethanol solution for 2 minutes and at the final stage, the seeds are soaked in sterile water for 16 hours. The Transfer of seeds in sterile water is carried out in a laminar airflow cabinet. The results showed that this sterilization method was very effective in suppressing contaminants from fungi and bacteria. After the seeds were stored in the incubator for 16 hours, then the sterilized seeds were sown on MS0 media. The seeding is done in a cabinet (laminar cupboard) to prevent contaminants. Mini tomato seeds will grow (germinate) for 7-14 days after sowing in an incubation room where temperature and humidity are maintained. During germination, the mini tomatoes will appear cotyledons first (Figure 2). The cotyledons were cut into two parts for transfer to the new MS media. Callus transfer activities are carried out in laminar cabinets to prevent contamination. Every two weeks, a mini tomato callus was cut and transferred to the callus induction medium. Then transferred to root induction media when roots have grown (Figure 3 ). The final stage of this mini tomato in-vitro process is acclimatization.

The ripening process of 'Micro-Tom' fruit is divided into four stages: mature green fruit stage (3033 Day Post Anthesis (DPA)); yellow fruit stage (32-33 DPA); orange fruit stage (33-35 DPA); and red fruit stage (41-45 DPA) [7]. We successfully developed of Micro-Tom until the root induction stage. We will use this tomato for genomic study in the next research (DNA extraction, PCR, etc). Research of lipocalin proteins in tomato Micro-Tom [8] suggested that lipocalin SITILs and SlCHL genes have a function for heat and oxidative stresses. The cytological analyses of lipocalin indicated that the overly expressed lipocalin gene can expand pericarp cells, meaning that the lipocalin gene contributes to increasing fruit growth relative to fruit set and during fruit maturation. This research 
reveals the key role of lipocalin in regulating fruit development [9]. The results of this study were suggested that mini tomato can used for genomic study such as DNA analyses and proteomic analyses.

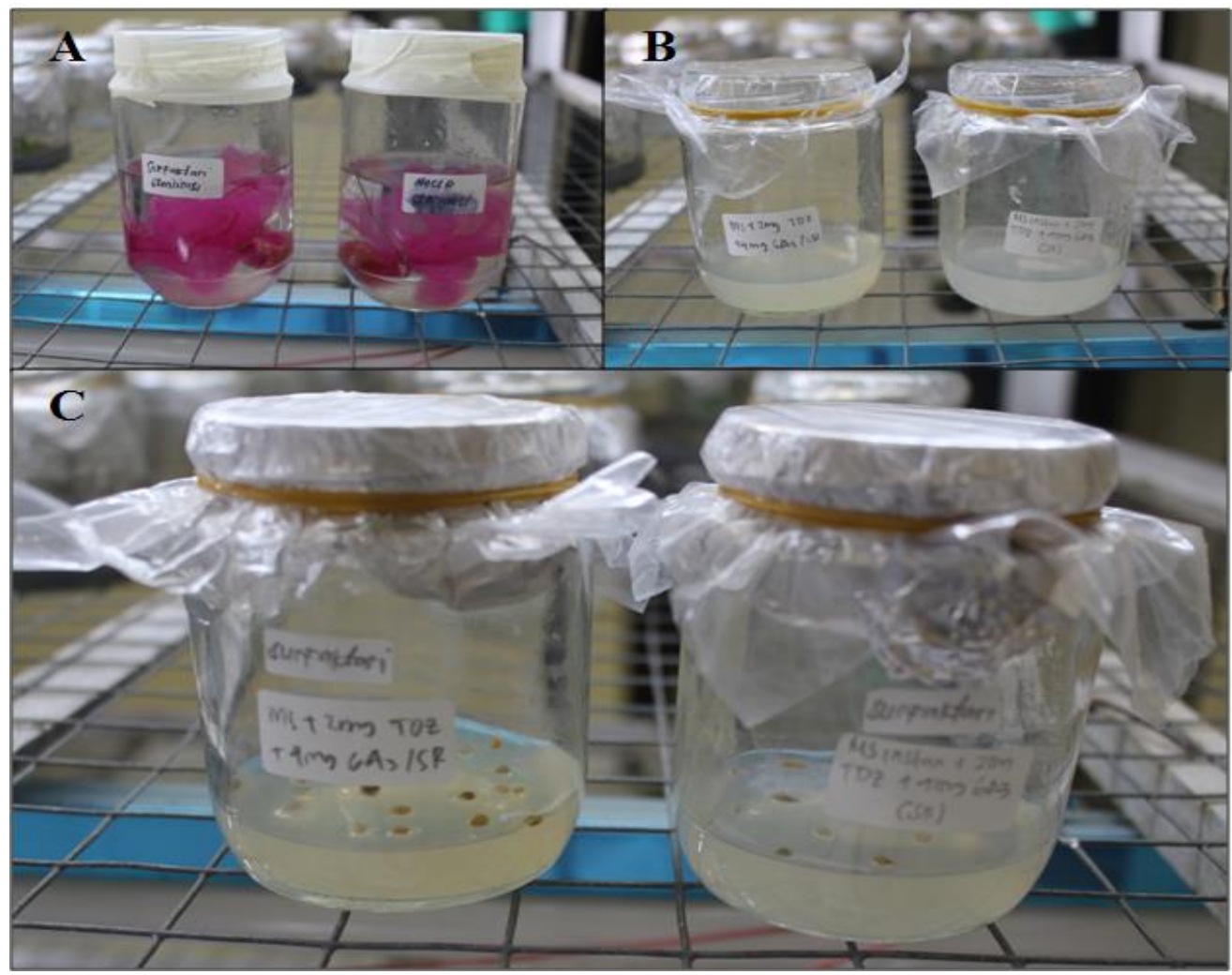

Figure 2. Sterilization and germination of Micro-Tom. A. Sterilization of seeds, B. Media of germination, C. Sowing of Micro-Tom seeds.

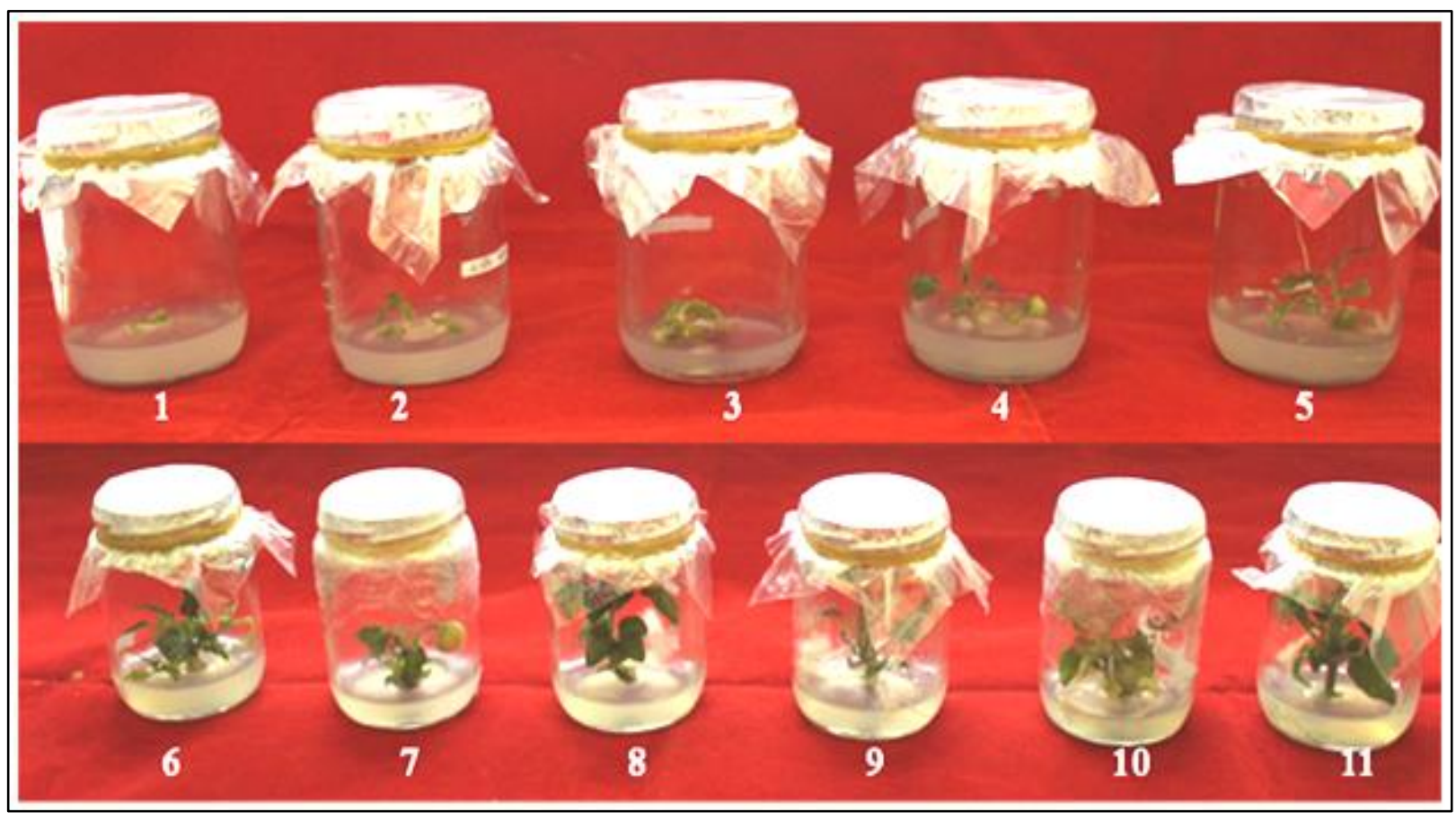

Figure 3. The development of Micro-Tom from callus induction to final root induction. 


\section{Conclusion}

We successfully developed a mini tomato until final root induction. The result of these studies will use for genomic study (next research).

\section{Acknowledgement}

This work was supported by Politeknik Negeri Lampung (DIPA 2020) and our students (Sekar Mustika Arum, Reni Rahmawati, and Febri Kurnia Sari).

\section{References}

[1] Wahyudi A 2018 Functional Analyses of Lipocalin Proteins InTomato Ph.D Thesis Shizuoka University Japan

[2] Wahyudi A, Ariyani D, Ma G, Inaba R, Fukasawa C, Nakano R andMotohashi R 2018 Functional analyses of lipocalin proteins in tomato Plant Biotech35 (4) 303-312

[3] Emmanuel E and Levy AA 2002Tomato mutants as tools for functional genomics Current Opinion in Plant Biology5 (2) 112-117 https://doi.org/10.1016/S1369-5266(02)00237-6

[4] Martí E, Gisbert C, Bishop G J, Dixon M S and García-Martínez J L2006 Genetic and physiological characterization of tomato cv. Micro-Tom, Journal of Experimental Botany57 (9) 2037-2047 https://doi.org/10.1093/jxb/erj154

[5] Lima, J E, Carvalho R F, Neto A T, Figueira A and Peres L E 2004 Micro-MsK: a tomato genotype with miniature size, short life cycle and improved in vitro shoot regenerationPlant Science167 (4) 753-757

[6] Campos M L, Carvalho R F, Benedito V A and Peres L E P 2010 Small and remarkable: the Micro-Tom model system as a tool to discover novel hormonal functions and interactions Plant Signaling and Behavior 5 (3) 267270

[7] Suzuki M, Takahashi S, Kondo T, Dohra H, Ito Y, Kiriiwa Y, Hayashi M, Kamiya S, Kato M, Fujiwara M, Fukao Y, Kobayashi M, Nagata N and Motohashi R 2015 Plastid proteomic analysis in tomato fruit development PLoS ONE10 (9): e0137266

[8] Wahyudi A, Fukazawa C, Motohashi R 2020 Function of SlTILs and SlCHL under heat and oxidative stresses in tomato Plant Biotech37 (3) 335-341 DOI: 10.5511/plantbiotechnology.20.0422a

[9] Wahyudi A, Fukazawa C, Motohashi R 2019 Cytological analyses of over-expressed SlTILs and SlCHL in tomato AIP Conference Proceedings2202, 020080 https://doi.org/10.1063/1.5141693 